CARDIOVASCULAR MEDICINE

\title{
Status of rheumatic heart disease in rural Pakistan
}

\author{
S F Rizvi, M A Khan, A Kundi, D R Marsh, A Samad, O Pasha
}

Heart 2004;90:394-399. doi: 10.1136/hrt.2003.025981

See end of article for authors' affiliations .....................

Correspondence to: Omrana Pasha, MD, 1330 Briavista Way, Atlanta, GA 30329, USA;

omranapasha@

yahoo.com

Accepted

4 September 2003

\begin{abstract}
Objectives: To determine the community based prevalence of rheumatic heart disease (RHD) in the rural population of the district of Rahim Yaar Khan in Pakistan.

Subjects and methods: A representative sample of the rural population of Rahim Yaar Khan district was selected. RHD was screened for by physical examination and the diagnosis was confirmed with echocardiographic Doppler studies. Sociodemographic data on each screened person were collected.

Results: 54 cases of RHD were found among the 9430 people screened (prevalence of 5.7 in 1000, 95\% confidence interval 4.2 to 7.2 ). Females were significantly more likely to be affected. There was no significant relation with other factors studied (education, crowding, and socioeconomic status). Less than $20 \%$ of those found to have RHD were aware of their diagnosis before participation in this study and only three affected people (8\%) were taking rheumatic prophylaxis.

Conclusions: There is a high prevalence of RHD among the rural population of Pakistan. The prevalence has not declined over the past three decades. Nearly all people with RHD, including most of those who know their diagnosis, do not receive the benefit of potentially life saving secondary prevention measures.
\end{abstract}

$\mathrm{R}$ heumatic fever and rheumatic heart disease (RHD) are endemic in Pakistan. ${ }^{12}$ RHD is one of the leading causes of premature death and disability in Pakistan. ${ }^{3}$ Community based studies of RHD prevalence were last conducted in the $1960 \mathrm{~s}^{4}$ and $1970 \mathrm{~s}^{5}$ (table 1). ${ }^{4-9}$ The former survey was limited to male patients and the latter to those above the age of 30 years. Both showed a prevalence of RHD of about 6 in 1000. However, these studies were nonrandomised and not based on echocardiographic diagnosis. More recent epidemiological data are limited to school surveys $^{6-9}$ and facility based reports ${ }^{10-12}$ (tables 1 and 2). Because of low enrolment rates and frequent absenteeism, school based studies are unlikely to reflect accurately the epidemiology of RHD in Pakistan. In Pakistan, where few people seek preventative care, facility based data are unlikely to reflect the true prevalence in the community. As most tertiary care centres in Pakistan are located in urban areas, these studies are not representative of the larger rural population.

The majority of the population of Pakistan (67.5\%) lives in rural areas ${ }^{13}$ and may bear the greatest burden of RHD mortality and disability in Pakistan. However, there are no community based data regarding the prevalence and distribution of echocardiography proven RHD in this population. We conducted this study to determine the prevalence of RHD in a rural population in a single subdistrict and studied the risk factors for RHD.

\section{METHODS \\ Setting}

We conducted the study in a "tehsil" (subdistrict) of Rahim Yaar Khan district. The district lies at the borders of the largest, most populous of Pakistan's four provinces, Punjab, and Sindh, the second most heavily populated province, and covers an area of $11800 \mathrm{~km}^{2}$. The weather is generally dry and hot with sparse precipitation. The census of 1998 shows the population of Rahim Yaar Khan district to be 3.1 million, of whom 2.5 million $(80 \%)$ reside in rural areas. The main occupation is agriculture. A typical family's income is Pakistan 1000 rupees (US\$17) a month. The average family size is seven people, and $70 \%$ of the houses are constructed with semipermanent materials. The overall literacy rate is
18\%. The Sheikh Zayed Hospital, a 650 bed facility, provides the majority of tertiary medical care for the people of this area.

\section{Sampling technique}

We estimated sample size based on the following assumptions: firstly, the rural population of the tehsil at the time of the study was 663254 (based on the 1981 census with an annual growth rate of $3.4 \%$ ); and secondly, the prevalence of RHD in the population was 6 in $1000 .{ }^{1}$ We calculated that a sample of 4700 people would suffice to measure a prevalence of $0.6 \% \pm 0.25 \%$ with $95 \%$ confidence. We multiplied this number by a correction factor of 2 to account for the cluster sampling method we used, yielding a final sample size of 9400. We expected to find this number of people in 1343 households of seven people each. We rounded the number of households to 1400 to account for refusals.

We divided the tehsil into seven equal clusters and used random number tables to select a single village in each cluster. We surveyed all the households in each village. In cases where fewer than 200 households were present in a single village, we surveyed the neighbouring village to complete the required number, yielding a total of 11 villages.

\section{Survey methods}

We conducted the study in two rounds, initially gathering socioeconomic and demographic details for each household and its individual inhabitants and later returning for a screening examination of each household member by a cardiologist. We attempted to find missing household members at repeat visits and examined people at their farms or schools if necessary. On average, we visited each household twice. The survey was conducted at the time of minimum crop activity and maximum availability of villagers at their homes (November 1993 to March 1994).

During the first round we gathered the sociodemographic variables age, sex, occupation, and literacy (based on ability to read and write a simple letter). We assessed socioeconomic status based on ownership of common household items such as livestock, electronic items, and vehicles. We assigned scores ranging from 0.05 for poultry to 100 for a tractor based on the estimated cost of each item in the local currency. We 
Table 1 Surveys to measure the prevalence of rheumatic heart disease (RHD) in Pakistan

\begin{tabular}{|c|c|c|c|c|c|c|}
\hline \multirow[b]{2}{*}{ Reference (year of study) } & \multirow[b]{2}{*}{ Site } & \multirow[b]{2}{*}{ Survey type } & \multicolumn{2}{|l|}{ Population } & \multirow[b]{2}{*}{ Sample size } & \multirow{2}{*}{$\begin{array}{l}\text { RHD prevalence } \\
\text { (per } 1000 \text { population) }\end{array}$} \\
\hline & & & Age (years) & Sex & & \\
\hline Hashmi $^{4}$ (1963-64) & Sindh (urban and rural) & Community & $20-80$ & Male & 2146 & 6 \\
\hline \multirow[t]{2}{*}{ Syed et a $\left.\right|^{5}(1967-8)$} & Karachi (urban) & Community & $30-60$ & Both & 1785 & 5.9 \\
\hline & Punjab (rural) & & & & 2412 & 6.7 \\
\hline Abbasi et al ${ }^{6}$ (1968) & Karachi (urban) & School & $8-14$ & Both & 4003 & 1.8 \\
\hline \multirow[t]{2}{*}{ llyas et aP (1979) } & Peshawar (urban) & School & $5-15$ & Both & 17662 & 7 \\
\hline & Chitral (rural) & & & & 2678 & 11 \\
\hline Malik et $a^{\beta}$ (1981) & Islamabad (urban) & School & $5-15$ & Both & 15100 & 1.5 \\
\hline WHO global programme for the & Islamabad & School & $5-15$ & Both & 15831 & 0.6 \\
\hline prevention of rheumatic fever/ & Rawalpindi & & & & 945 & 7 \\
\hline rheumatic heart disease 9 (1988) & Peshawar & & $6-18$ & & 2243 & 1.7 \\
\hline & Quetta & & & & 2000 & 1 \\
\hline & Hyderabad & & & & 2000 & 0.5 \\
\hline
\end{tabular}

measured crowding based on the number of household members and number of rooms in the house, ranging from one (single room with five or more people) to three (three rooms with fewer than five people or more than three rooms).

In the second round the medical team consisting of a cardiologist (SFHR) and his associate (MAK) visited each household. This team performed cardiac auscultation on each patient in the supine and left lateral decubitus position in quiet surroundings. In cases where a murmur was heard, the other physician rechecked the findings. An echocardiographic examination with a Toshiba SSH-60A echocardiographic system (Tokyo, Japan) was carried out for persons found to have any of the following abnormalities: diastolic murmur, systolic murmur of grade $2 / 6$ or more, abnormal heart sounds, or any other important clinical findings suggestive of organic heart disease. We collected detailed information for all patients with echocardiographically proven RHD, including a medical history, physical examination, and laboratory tests (that is, 12 lead ECG, chest $x$ ray, throat swabs for bacterial culture and sensitivity studies, and complete blood count). We categorised each patient according to New York Heart Association (NYHA) functional class. We collected details of any manifestations of rheumatic fever from each patient and their family members according to the updated 1992 Jones criteria of the American Heart Association task force on rheumatic fever/rheumatic heart disease, ${ }^{14}$ as well as a history of heart valve disease, rheumatic prophylaxis, and cardiac surgery.

\section{Data management and statistical analysis}

We double entered the data on Epi-Info version $6^{15}$ and used SPSS version 8 for data analysis (SPSS Inc, Chicago, Illinois, USA). We calculated estimates of prevalence of RHD in the study population with $95 \%$ confidence intervals (CI). We calculated the odds ratio for the presence of each categorical variable under study among those with and without RHD.
We used Cornfield's approximation to estimate 95\% CI. We compared the means of each continuous variable under study between those with and those without RHD by using Student's $t$ test for two independent samples.

\section{RESULTS}

We surveyed a total of 1311 households in 11 villages, obtained sociodemographic information for 10412 people, and screened 9483 people (91.1\%) for RHD. Among the 8.9\% of people not included in the study, $2.6 \%$ refused to take part in the study, and the rest were not found despite repeated home visits.

The population we surveyed lived in crowded conditions, each household having an average of 8 members living in 2.3 rooms. The families were poor, $61 \%$ earning less than 2000 rupees a month (median income of 1000 rupees a month). Half of the population was under 15 years of age. The sex ratio was 113 males to 100 females. The overall literacy rate was $18 \%$.

On initial screening, 404 (4.3\%) people had a murmur; however, only $256(2.7 \%)$ met the criteria for further assessment. The remaining 148 people (1.6\%) had innocent murmurs and did not require further investigation. Eighty per cent (203 or 256) of the patients with suspicious murmurs underwent echocardiography and Doppler studies to define the cause of murmur. We diagnosed no organic heart disease in 96 of the 203 patients. Overall 47 patients had RHD and another seven patients had RHD with associated congenital heart disease. We diagnosed proven RHD in 54 people, for a prevalence of 5.7 in 1000 (95\% CI 4.2 to 7.2 ) in the screened population (fig 1 ).

The 53 people who refused further investigation after a murmur was detected on a screening examination did not differ significantly from those who underwent the tests $(n=203)$ with regard to age, sex, marital status, or education (table 3 ). The patients who were eligible for echocardiography belonged to 210 households. All the

Table 2 Hospital based data on RHD in Pakistan

\begin{tabular}{lllll}
\hline Reference (year of study) & Site & Age (years) & Total admissions & \% RHD \\
\hline Robinson ef al ${ }^{10}$ (1965) & Karachi & $5-22$ & $?$ & 1.0 \\
Rahimatoola et al 11 (1972-5) $^{12}$ & JPMC Karachi & $<15$ & 3120 & 3.5 \\
Aziz ${ }^{12}$ (1980-3) & NICVD Karachi & $4-12$ & 2824 & 9 \\
WHO global programme for & NICVD Karachi & All ages & 2594 & 2 \\
prevention of rheumatic fever/ & Mayo Hospital Lahore & All ages & 1760 & 29 \\
rheumatic heart disease (1988) & Peshawar & All ages & Unknown & 20 \\
& Quetta & All ages & 832 & 22 \\
\hline
\end{tabular}

JPMC, Jinnah Postgraduate Medical Centre; NICVD, National Institute of Cardiovascular Diseases. 


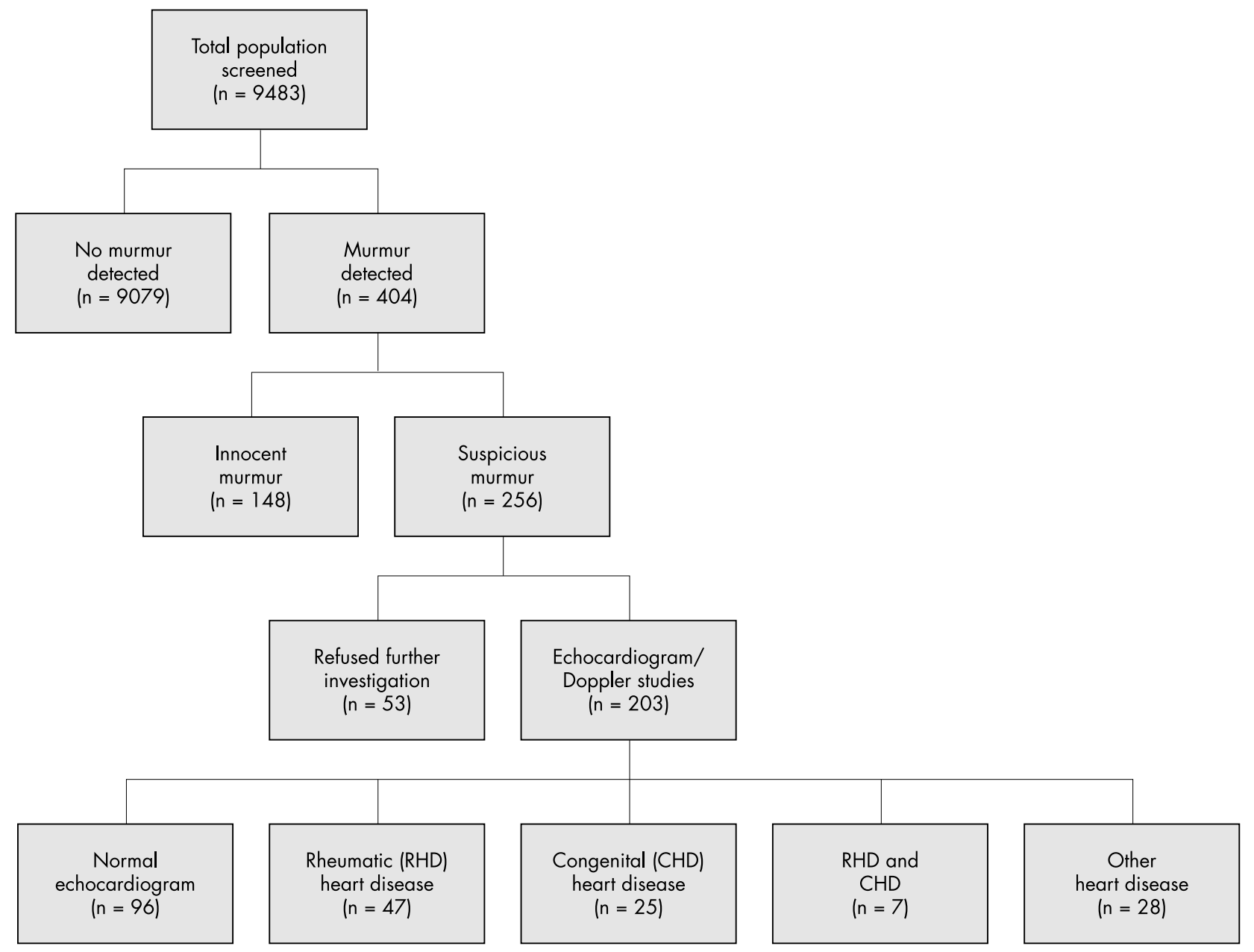

Figure 1 Outcome of screening for rheumatic heart disease in the study population.

Table 3 Sociodemographic and household characteristics of patients with murmurs by participation in cardiac investigation

\begin{tabular}{|c|c|c|c|}
\hline Sociodemographic factors & $\begin{array}{l}\text { Participants } \\
(\mathrm{n}=203)\end{array}$ & $\begin{array}{l}\text { Non-participants } \\
(n=53)\end{array}$ & $\begin{array}{l}\text { OR }(95 \% \mathrm{Cl}) \text { or } \\
\text { p value }\end{array}$ \\
\hline Age (years) & $32.6(23.1)$ & 29.5 (18.2) & 0.37 \\
\hline \multicolumn{4}{|l|}{ Sex } \\
\hline Female & $28(53 \%)$ & $88(43 \%)$ & 0.21 \\
\hline Male & $25(47 \%)$ & $115(57 \%)$ & $1.46(0.80$ to 2.68$)$ \\
\hline \multicolumn{4}{|c|}{ Marital status among patients $\geqslant 10$ years old } \\
\hline Ever married & $28(64 \%)$ & $118(64 \%)$ & 0.91 \\
\hline Never married & $16(36 \%)$ & $65(36 \%)$ & $0.96(0.49$ to 1.91$)$ \\
\hline \multicolumn{4}{|l|}{ Literacy among patients $\geqslant 5$ years old } \\
\hline Illiterate & $25(51 \%)$ & $105(54 \%)$ & 0.72 \\
\hline Able to read or having any formal education & $24(49 \%)$ & $90(46 \%)$ & $0.89(0.48$ to 1.67$)$ \\
\hline \multicolumn{4}{|c|}{ House construction } \\
\hline $\begin{array}{l}\text { "Pucca" (walls and roof built of concrete or } \\
\text { brick) }\end{array}$ & $12(30 \%)$ & $52(32 \%)$ & 0.83 \\
\hline $\begin{array}{l}\text { Semipucca or "kutcha" (walls or roof built } \\
\text { of asbestos sheeting, card board, etc) } \\
\text { Sanitation }\end{array}$ & $28(70 \%)$ & 112 (68\%) & 0.92 (0.44 to 1.96$)$ \\
\hline No latrine within the house & $9(22 \%)$ & $26(17 \%)$ & 0.44 \\
\hline Latrine within the house & $32(78 \%)$ & $129(83 \%)$ & $0.68(0.30$ to 1.52$)$ \\
\hline Socioeconomic score & $9021.0(7145.5)$ & $9120.0(5625.6)$ & 0.95 \\
\hline Crowding score & $1.59(0.95)$ & $1.32(1.05)$ & 0.12 \\
\hline
\end{tabular}

Data are mean (SD) for continuous variables or number (\%) for categorical variables. $\mathrm{Cl}$, confidence interval; OR, odds ratio. 
eligible members of 41 households refused to undergo further testing, and all those in 166 households agreed to participate. In three of the households, some members agreed to undergo echocardiography and some refused to participate. There were no differences between the households with members who agreed to participate and those with members who refused with regard to household construction, presence of a latrine within the house, crowding score, and socioeconomic score (table 3).

We did not find any cases of RHD among children aged 0-4 years. People with RHD were significantly older than those without RHD (mean age $29.5 \vee 20.9$ years, p < 0.005). However, we found no consistent pattern of RHD prevalence with age (fig 2). Interestingly, females were almost twice as likely to be affected by RHD as males. Among the 4508 females screened, 34 (7.5 in 1000, 95\% CI 5.0 to 10.1) cases of RHD were detected, whereas only 20 (4.1 in 1000, 95\% CI 2.3 to 5.8$)$ cases were found among the 4921 males screened (odds ratio $1.86,95 \%$ CI 1.07 to 3.24 ). The highest rate of RHD (22.0 in $1000,95 \%$ CI 4.6 to 39.4 ) was found among women aged $45-54$ years.

We looked at the marital status of only those people who were at least 10 years of age. Fifty one of the people with RHD were 10 years old or more, and $33(65 \%)$ of them had ever been married. Among those without RHD, 6085 were above the age of 9 years and 3656 (60\%) of them had ever been married. We looked at the literacy status of all those people who were 5 years of age or more. All 54 people with RHD were $\geqslant 5$ years of age and $29(54 \%)$ of them were illiterate. Among the people without RHD, 7714 were 5 years of age or more and 4019 (52\%) of them were illiterate.

We assessed risk factors for the 50 households where we found the 54 patients with RHD. There was no difference in house construction between households that had and those that did not have members with RHD (30.0\% (15 of 50) $v$ $32.1 \%$ (385 of 1201$)$ ). Only 7 of the 50 (14\%) households with RHD cases had a latrine within the house compared with 237 of the 1219 (19.4\%) households without RHD cases. Households with RHD were somewhat more crowded than those without RHD (mean crowding score $1.42 v 1.31$ ). Similarly, the socioeconomic score was higher for the RHD group (9113.9 $v$ 8507.0). However, neither the difference in socioeconomic score nor that in crowding score reached significance. None of the personal or household factors was significantly associated with the presence of RHD in our population (table 4 ).

Among the 54 households where RHD was detected, in four RHD was diagnosed in more than one member. In each of these families two siblings were found to have the disease.
Only 10 (19\%) of the 54 patients found to have RHD were aware of their valvar disease before the study. Only three $(8 \%)$ of the study patients with RHD were taking rheumatic prophylaxis. A history of symptoms of rheumatic fever was elicited from $56 \%$ (30) of the patients. The majority of patients $(53 \%$ ( 29 of 54$)$ ) were in NYHA class II. A fourth of them ( $25 \%$ ( 13 of 54$)$ ) were minimally symptomatic - that is, in NYHA class I. Of the remaining 11 patients, eight were in NYHA class III and three in class IV.

Seventeen $(31 \%)$ of the 54 patients with RHD had a combination of aortic and mitral valve disease; 13 (24\%) had mitral stenosis; 11 (21\%) had mitral regurgitation; and 8 (15\%) had both mitral stenosis and mitral regurgitation. Other diagnoses were aortic regurgitation (5\% (3 of 54)), aortic regurgitation and stenosis (2\% ( 1 of 54$)$ ), and combined mitral and tricuspid valve disease ( $2 \%$ ( 1 of 54$)$ ).

Juvenile RHD, a malignant form of the disease seen in young people described in South Asia, ${ }^{16}$ was common in our sample. Twenty three of the 54 patients (43\%) were 20 years of age or less.

\section{DISCUSSION}

There is a high prevalence of RHD among the rural population of Rahim Yaar Khan. There has been little or no decline in the occurrence of RHD in the rural population of Pakistan over the past three decades (table 1). Unfortunately, there are few comparable studies describing the prevalence of RHD in rural communities in South Asia, particularly in Pakistan.

The preponderance of female patients with RHD in our study differs from the conventional epidemiological picture of rheumatic fever of equal prevalence among males and females. ${ }^{17}$ Recent studies from developing countries show an inconsistent association between sex and RHD. Some studies from South Asia, ${ }^{18}$ the Middle East, ${ }^{19}$ and North Africa ${ }^{20} 21$ show that females are more likely than males to have RHD. Conversely, other studies from these regions show that there are no differences in the sex specific prevalence of RHD. ${ }^{22} 23$ None of the studies we reviewed were able to identify an explanation for the difference in sex specific prevalence. However, Padmavati ${ }^{24}$ has suggested that the high rates of RHD among females in India can be attributed to the likelihood that women are housebound, thus more likely to be exposed to overcrowding. We did not see an association between overcrowding and RHD in our study, although current crowding may differ from that present during the onset of the disease. The cause for high rates of RHD among women in our population is not clear. However, in the rural Pakistani population RHD poses a great threat to women's

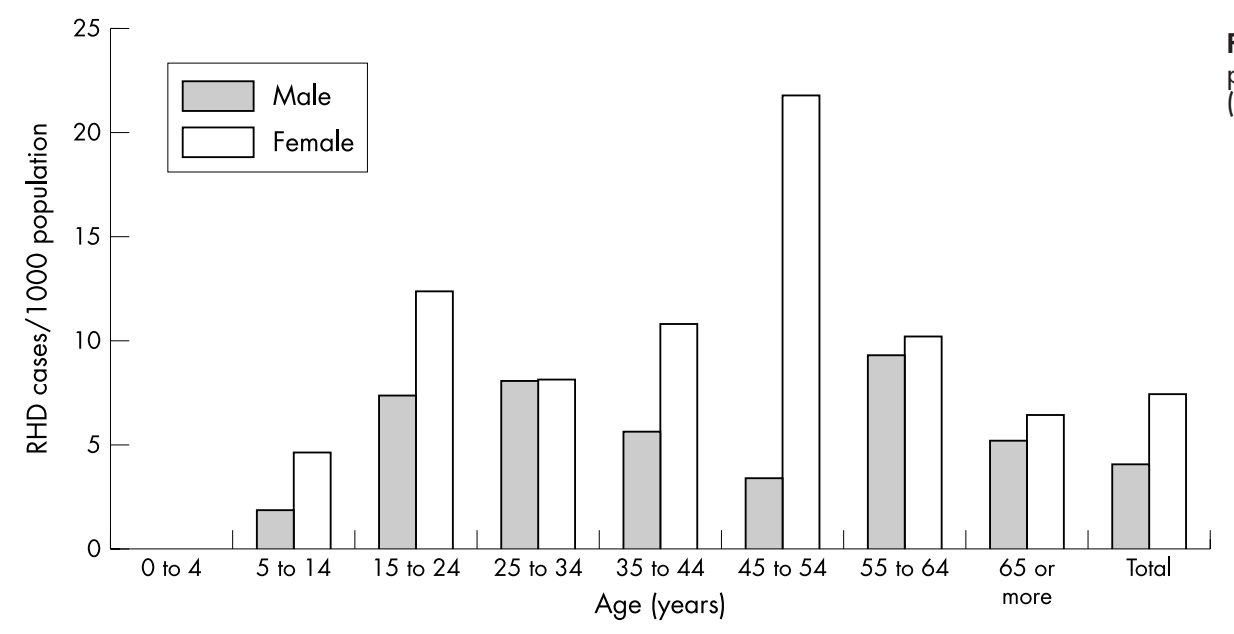

Figure 2 Age and sex specific prevalence of rheumatic heart disease (RHD). 
Table 4 Sociodemographic and household characteristics by RHD status

\begin{tabular}{|c|c|c|c|}
\hline Sociodemographic factors & $\begin{array}{l}\text { RHD cases } \\
(n=54)\end{array}$ & $\begin{array}{l}\text { No RHD cases } \\
(\mathrm{n}=9429)\end{array}$ & OR $(95 \% \mathrm{Cl})$ or $\mathrm{p}$ value \\
\hline Age (years) & $29.5(16.8)$ & $20.95(18.8)$ & $<0.005$ \\
\hline \multicolumn{4}{|l|}{ Sex } \\
\hline Female & $34(63 \%)$ & $4474(48 \%)$ & 0.02 \\
\hline Male & $20(37 \%)$ & 4901 (52\%) & $1.86(1.07$ to 3.24$)$ \\
\hline \multicolumn{4}{|c|}{ Marital status among patients $\geqslant 10$ years old } \\
\hline Ever married & $33(65 \%)$ & $3656(60 \%)$ & 0.50 \\
\hline Never married & $18(35 \%)$ & $2429(40 \%)$ & 1.21 (0.68 to 2.17$)$ \\
\hline \multicolumn{4}{|l|}{ Education among patients $\geqslant 5$ years old } \\
\hline Illiterate & $29(54 \%)$ & 4019 (52\%) & 0.81 \\
\hline $\begin{array}{l}\text { Able to read or having any formal } \\
\text { education }\end{array}$ & $25(46 \%)$ & $3695(48 \%)$ & $1.07(0.62$ to 1.82$)$ \\
\hline \multicolumn{4}{|l|}{ House construction } \\
\hline Pucca & $15(30 \%)$ & $385(32 \%)$ & 0.76 \\
\hline Semipucca or kutcha & $35(70 \%)$ & $816(68 \%)$ & $0.91(0.49$ to 1.68$)$ \\
\hline \multicolumn{4}{|l|}{ Sanitation } \\
\hline Latrine within the house & $7(14 \%)$ & $237(19 \%)$ & 0.34 \\
\hline No latrine within the house & $43(86 \%)$ & $982(81 \%)$ & $0.68(0.30$ to 1.52$)$ \\
\hline Socioeconomic score & 9113.9 (5309.7) & 8507.0 (8993.0) & 0.60 \\
\hline Crowding score & $1.42(0.95)$ & $1.31(0.97)$ & 0.41 \\
\hline
\end{tabular}

health, as health care seeking for women is constrained by sociocultural norms. The delay in the diagnosis of mild to moderate disease among women may lead to a large population of female patients in the advanced stages of RHD. The large number of cases (35\%) in the age group below 20 years is also a cause for concern. This puts a large burden of a disabling condition on a young population.

One of our most troublesome findings is that few $(8 \%)$ of the people with known RHD were aware of the need for rheumatic or subacute bacterial endocarditis prophylaxis. Even those who knew their diagnosis were living without potentially life saving secondary prevention measures.

We did not detect a significant socioeconomic difference in the prevalence; however, this may be due to the overall poverty prevailing in the area.

The prevalence of RHD in Rahim Yaar Khan subdistrict is 5.7 in 1000. Assuming that this is the rate of RHD throughout the rural population of Pakistan ( 88 million), ${ }^{12}$ there are more than 500000 patients with RHD in rural Pakistan. Few of these patients ever seek a tertiary care centre where suitable treatment is available. Furthermore, among those who do reach the appropriate facilities, only a small fraction undergo definitive treatment. In 1988 about 4000 patients with RHD presented to the outpatient department of the National Institute of Cardiovascular Diseases, Karachi, and only 13\% of them were offered surgery. The most likely reason for this is the prohibitive cost of the procedure.

These data paint an alarming picture of the high prevalence of RHD in a resource constrained environment where access to health care is limited. The high number of female patients with undetected disease, the high proportion of patients with RHD who are 20 years of age or less, and non-use of rheumatic prophylaxis underscore the need for cost effective preventive measures at the national level. Primary prevention, although ideal, is difficult to achieve in large populations, so secondary prophylaxis remains the most practical solution. It can be achieved through primary care facilities, school health centres, maternal and child health services, and paediatric and cardiology departments. Unfortunately, because of a lack of vision, resources, and coordination no system exists in Pakistan, where rheumatic fever and RHD remain major unresolved health problems.

\section{ACKNOWLEDGEMENTS}

We are indebted to the members of the field team and the hospital staff. We are particularly grateful to Iqbal Azam, who assisted with questionnaire design and data analysis. We also thank Zubaida Ellahi and Sohail Aslam for secretarial support.

\section{Authors' affiliations}

S F Rizvi, Cardiology Department, Sheikh Zayed Hospital, Rahim Yaar Khan, Pakistan

M A Khan, Sheikh Zayed Hospital, Rahim Yaar Khan, Pakistan A Kundi, A Samad, National Institute Of Cardiovascular Diseases, Karachi, Pakistan

D R Marsh, Community Health Sciences, The Aga Khan University, Karachi, Pakistan

O Pasha, Office of Health, International Programs, Save the Children Federation, Inc, Westport, Connecticut, USA

\section{REFERENCES}

1 Anon. WHO Cardiovascular Diseases Unit. WHO programme for the prevention of rheumatic fever/rheumatic heart disease in 16 developing countries: report from phase I (1986-1990) Bull World Health Organ 1992:70:213-8.

2 Eisenberg MJ. Rheumatic heart disease in the developing world: prevalence, prevention and control. Eur Heart $J$ 1993;14:122-8.

3 Hyder AA, Morrow RH. Applying burden of disease methods in developing countries: a case study from Pakistan. Am J Public Health 2000;90:1235-40.

4 Hashmi JA. An epidemiological study of heart disease in Pakistan. J Pak Med Assoc 1966; 18:544.

5 Syed SA, Raza M, Hashmi JA. Establishment of comprehensive research and rehabilitation program for persons of various forms of heart disease. Project. V R A Pak. Karachi: National Institute of Cardiovascular Disease, 1973:8-66.

6 Abbasi AS, Hashmi JA, Robinson RD, et al. Prevalence of heart disease in school children of Karachi. Am J Cardiol 1966;18:544.

7 Ilyas M, Peracha MA, Ahmed R, et al. Prevalence and pattern of rheumatic heart disease in the Frontier province of Pakistan. J Pak Med Assoc 1979;29:165-79.

8 Malik SM, Jaffery S, Ahmed S, et al. Prevalence of heart disease in school children of Islamabad. Pak Heart J 1981;14:2.

9 Proceedings of Second National Workshop on WHO Global Programme for Prevention of Rheumatic Fever/Rheumatic Heart Disease, Islamabad, 10-12 June 1989.

10 Robinson RD, Sultanna S, Abbasi AS, et al. Acute rheumatic fever in Karachi, Pakistan. Am J Cardiol 1966;18:548-51.

11 Rahimatoola RJ, Shafagat H, Ramzan A. Acute rheumatic fever and rheumatic carditis in children. Pak Heart J 1980;13:2-8.

12 Aziz KU. Incidence of heart disease in children at the National Institute of Cardiovascular Diseases. J Pak Med Assoc 1984;34:300-5.

13 Anon. Government of Pakistan, Ministry of Finance. Economic survey 2000 2001. Table 12.4, Population by age, sex urban/rural areas 1981 and 1998 census. http://www.finance.gov.pk/survey/chapters/13-population.pdf (accessed 6 Dec 2003).

14 Dajani AS, Ayoub E, Bierman FZ, et al. Guidelines for the diagnosis of rheumatic fever: Jones criteria, updated 1992. Circulation 1993;87:302-7.

15 Burton AH, Dean JA, Dean AG. Software for data management and analysis in epidemiology. World Health Forum 1990;1 1:75-7.

16 Vijaykumar M, Narula J, Reddy KS, et al. Incidence of rheumatic fever and prevalence of rheumatic heart disease in India. Int J Cardiol 1992;43:221-8. 
17 Dajani AS. Rheumatic fever. In: Braunwald E, Zipes DP, Libby P, eds. Heart disease: a textbook of cardiovascular medicine, 6th edn. Philadelphia: WB Saunders, 2001:2192.

18 Agarwal AK, Yunus M, Ahmad J, et al. Rheumatic heart disease in India. J R Soc Health. 1995:115: 303-4, 309.

19 al-Sekait MA, al-Sweliem AA, Tahir M. Rheumatic heart disease in schoolchildren in western district, Saudi Arabia. JR Soc Health 1990;1 10:15-6, 19

20 Ibrahim-Khalil S, Elhag M, Ali E, et al. An epidemiological survey of rheumatic fever and rheumatic heart disease in Sahafa Town, Sudan. J Epidemiol Community Health 1992;46:477-9.
21 Oli K, Tekle-Haimanot R, Forsgren L, et al. Rheumatic heart disease prevalence among schoolchildren of an Ethiopian rural town. Cardiology 1992;80:152-5.

22 Thakur JS, Negi PC, Ahluwalia SK, et al. Integrated community-based screening for cardiovascular diseases of childhood. World Health Forum 1997:18:24-7.

23 Vashistha VM, Kalra A, Kalra K, et al. Prevalence of rheumatic heart disease in school children. Indian Pediatr 1993;30:53-6.

24 Padmavati S. Rheumatic heart disease: prevalence and preventive measures in the Indian subcontinent [editorial]. Heart 2001;86:127.

\section{IMAGES IN CARDIOLOGY}

\section{Subaortic stenosis caused by flail discrete membrane in an older patient}

A 69 year old women was admitted to our hospital because of new onset palpitation. Physical examination revealed a heart rate 135 beats/min and a blood pressure of 200/120 mm Hg. On auscultation of the heart, a grade $2 / 6$ systolic ejection murmur was heard at the third right intercostal space. Other physical findings were unremarkable. Electrocardiography revealed atrial fibrillation rhythm. Chest $x$ ray findings were non-specific. Heart rate was controlled with a $\beta$ blocker and blood pressure was lowered with an angiotensin converting enzyme inhibitor. The patient was transferred to echocardiography laboratory. Two dimensional echocardiographic examination revealed normal left ventricular size and function, and a highly mobile fibrous membrane attached the interventricular septum at the left ventricular outflow tract (LVOT) (below left, upper panel: AOV, aortic valve; LA, left atrium; LV, left ventricle). Aortic valves were fibrotic and a mild degree of aortic regurgitation was also detected. There was colour flow turbulence and $30 \mathrm{~mm} \mathrm{Hg}$ pressure gradient in systole at the LVOT. Transoesophageal echocardiography (TOE)
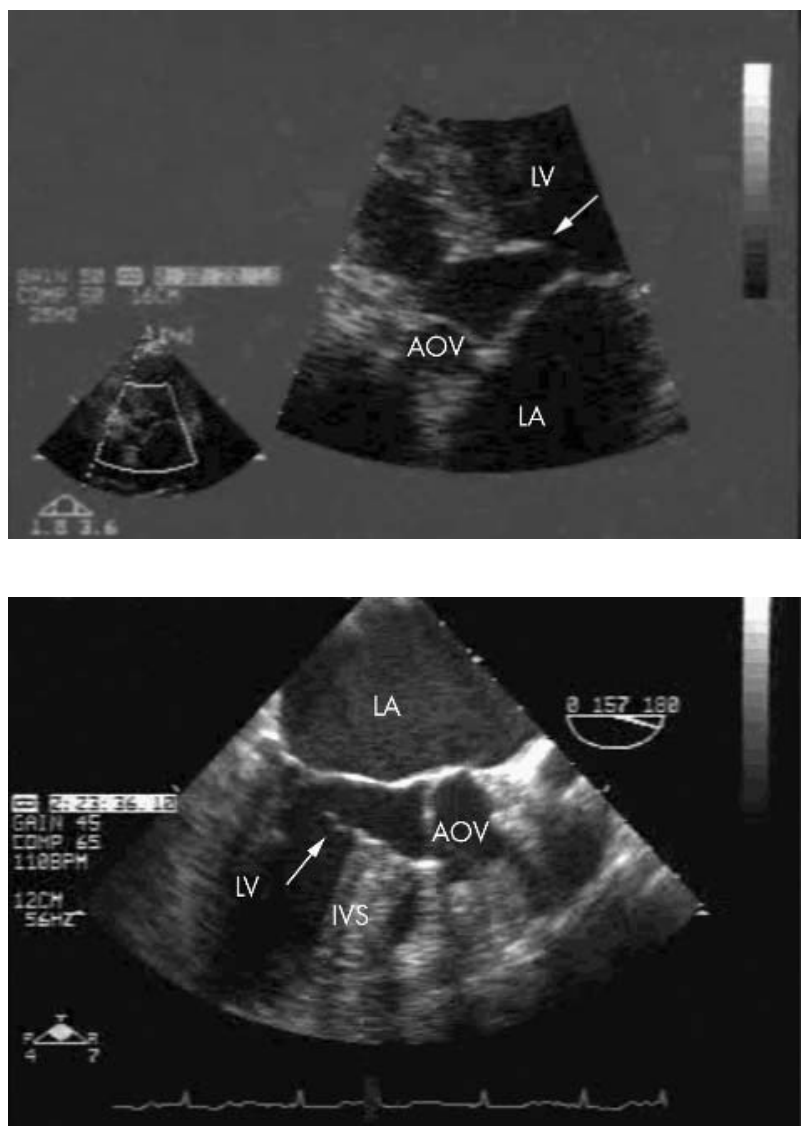

revealed left ventricular outflow obstruction caused by a discrete membrane which was highly mobile, moving to the left ventricular cavity in diastole and to the aortic valve in systole (below left, lower panel, and below right, upper panel: IVS, interventricular septum). Also, no thrombus was detected in the left atrium and left atrial appendage at TOE. Sinus rhythm was achieved by electrical cardioversion after unsuccessful medical cardioversion with propafenone and amiodarone. Cardiac magnetic resonance imaging confirmed the diagnosis of a discrete membrane at the level of the left ventricular outflow of the interventricular septum (below right, lower panel). Discrete suboartic membranes which cause subaortic stenosis are usually motionless. To the best of our knowledge, our patient was the first to be caused by flail suboartic discrete membrane.

A O Onbasili, T Tekten, C Ceyhan onbasili@isbank.net.tr
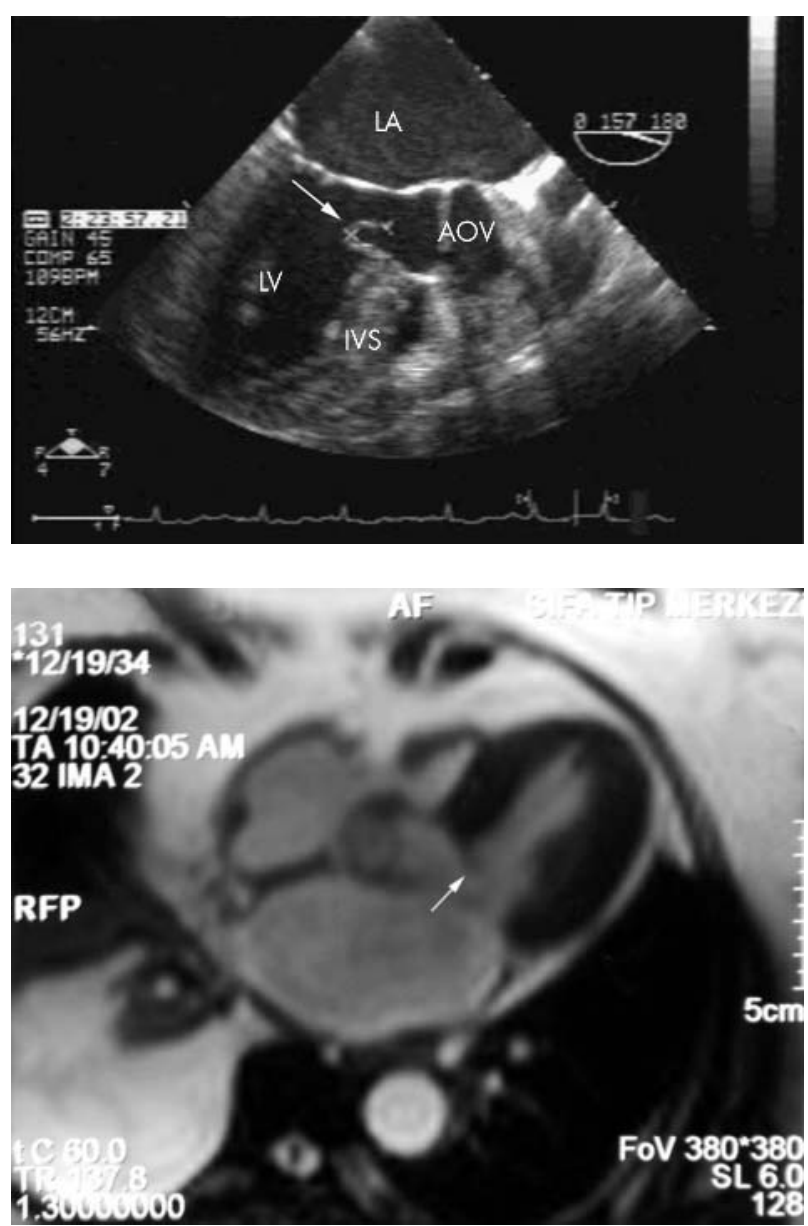